\title{
Airborne particles in snow
}

\author{
JOST HEINTZENBERG \\ Department of Meteorology, Stockholm University, S-10691 Stockholm, Sweden \\ MARKKU RUMMUKAINEN \\ Air Quality Department, Finnish Meteorological Institute, SF-00810 Helsinki, Finland
}

\begin{abstract}
In a pilot experiment, airborne particles were shown to exist in snow. In newly deposited snow they could be traced down to $17 \mathrm{~cm}$ below the surface. With our particle sensor, the snow was ventilated on the level of expected natural ventilation velocities. We show with a simple deposition model that air/snow exchange of airborne particles must be considered in the interpretation of impurities in snow and glacier ice. However, the relative magnitude of ventilation velocity compared to dry-deposition velocities at the surface is of crucial importance for determining total deposition. In particular, in ice sheets with high ventilation velocities, seasonal variations in atmospheric concentrations can be dampened and age distributions of deposited particles need to be considered similarly to the occlusion of gases.
\end{abstract}

\section{INTRODUCTION}

It has long been known that air transport occurs in snow. The related exchange of air between the atmosphere and the deposited snow influences the incorporation of gases and particles into glacier ice. Thus, this process needs to be taken into account when relating the concentrations of incorporated trace substances to corresponding atmospheric values. Our knowledge of the air/snow exchange of material is still very limited. Bader (1939) found strong air currents in snow. However, no diffusion coefficients could be derived from his data. Schwander (1989) identified three main causes of this transport: horizontal wind above the snow surface, barometric pressure variations and the densification process of the firn. In addition to this, Reuter (1948) has shown that convective mass exchange can be expected in snow with a strong diurnal variation in surface heat balance. In cold firn, on the other hand, Schwander argued that the mixing of air essentially is controled by molecular diffusion. He derived superficial air speeds near the surface of about $10^{-3} \mathrm{~cm} \mathrm{~s}^{-1}$ from measurements of diffusion coefficients on firn samples in the laboratory. Dubrovin (1961) found much larger velocities on the order of $1 \mathrm{~cm} \mathrm{~s}^{-1}$ at the $2 \mathrm{~m}$ depth level on the Lazarev Ice Shelf, Antarctica.

Tracer experiments in ambient snow are preferable to indirect estimates of the air exchange via micrometeorological or laboratory experiments. To our knowledge, no airborne tracer experiments had been performed prior to the present study. Profiles of deposited impurities, on the other hand, have been used to investigate air/snow exchange. Gjessing and Gjessing (1973) have determined profiles of major ions and metals down to $1 \mathrm{~m}$ snow depth and speculated that wind-pumping was responsible for the measured concentration decrease with depth. To test this hypothesis, Gjessing (1977) artificially ventilated snow samples from a $10 \mathrm{~m}$ profile prior to the analysis of deposited impurities. He found that a $1 \mathrm{~m}$ snow layer was not an absolute filter for impurities.

The study reported here comprises a pilot field experiment to demonstrate that airborne particles do exist in snow and that it is feasible to quantify their size distribution and the retention profile down to $20 \mathrm{~cm}$ below the snow surface. We will focus our attention on particles in the size range which is dominated by one of the major source processes for atmospheric processes. In this so-called accumulation mode $(0.1-2 \mu \mathrm{m}$ particle diameter), combustion and condensation processes control particle formation. Furthermore, atmospheric residence times are at a maximum (Whitby, 1978). These accumulation-mode particles can be distributed on a global scale. Thus, they are of greatest interest in paleoclimatological studies that build on aerosol particles deposited in the polar ice sheets.

\section{INSTRUMENTAL}

The core of the instrumentation is an optical particle counter (OPC). The instrument was developed by Knollenberg (1985) and is manufactured by Particle Measurement Systems, Inc., Boulder, Colorado. Nominally, the OPC counts particles in 32 channels between 100 and $7500 \mathrm{~nm}$. For our aerosol experiment we calibrated the instrument with ammonium sulfate particles of known size because $\left(\mathrm{NH}_{4}\right)_{2} \mathrm{SO}_{4}$ is the commonest material in the atmospheric aerosol below $1000 \mathrm{~nm}$ particle radius. Due to rapidly decreasing number concentrations with particle size, very long sampling times are necessary for sizes larger than about $2000 \mathrm{~nm}$. Therefore, and because 
of the consideration about particle source processes and atmospheric residence times mentioned above, we limited our experiment to particle sizes up to $2000 \mathrm{~nm}$. The volumetric sample flow of the instrument is $F_{\mathrm{OPC}}=$ $1 \mathrm{~cm}^{3} \mathrm{~s}^{-1}$.

The microcomputer-based data-acquisition program for the OPC allows us to record time series of particle-size distributions with a choice of averaging times betwen 1 and $64000 \mathrm{~s}$. The program also reads the mass flow of sample air through the sensor in order to calculate absolute particle concentrations. From the raw counts in the first 22 channels of the OPC, number concentrations in the form of $\mathrm{d} N / \mathrm{d} \log d_{\mathrm{p}}$ (units in $\mathrm{cm}^{-3}$ ) are calculated. By assuming that the particles are spherical, this numbersize distribution is used to calculate volume-size distribution as $\mathrm{d} V / \mathrm{d} \log d_{\mathrm{p}}\left(\right.$ as $\left.\mu \mathrm{m}^{3} \mathrm{~cm}^{-3}\right)$. The first and third moments of the size distributions yield total number $N$ and total volume $V$.

In order to determine particle profiles, this sensor was connected via a plenum and ten magnetic valves to ten identical inlets which could be arranged in any geometric configuration. To minimize particle losses on the way from the intake to the sensor (discussed in detail below), the length of the sample lines had to be kept to a minimum. Consequently, the plenum and valves had to be placed outdoors, close to the sampling site. No commercial valves were available that

(a) had small dead air volumes to minimize residence times,

(b) had sufficiently large openings to minimize particle losses, and

(c) worked at temperatures down to $-20^{\circ} \mathrm{C}$.

Thus, we built our own valves from small springloaded electromagnets and short silicone tubes which were pinched shut in the off position of the magnets. The valves were connected to the intake points by stainless steel tubes of internal diameter $1.05 \mathrm{~mm}$ having identical $2 \mathrm{~m}$ lengths. The same tubing was used in the star connection to the plenum and from the plenum to the OPC $(2.8 \mathrm{~m})$.

A controler opened the valves in cyclical order for preset lengths of time. It also sent a valve identification signal to the parallel port of the personal computer which ran the OPC. For simplicity of design, controler and OPC were not synchronized. However, the OPC software terminated any ongoing averaging process whenever the valve position changed in order to avoid mixed data from two inlets. A schematic picture of the total set-up is given in Figure 1.

A prerequisite for the determination of profiles of particle-size distributions with the above set-up is the quantification of particle losses as a function of their size in the different branches of the system. This loss measurement was achieved by comparing polydisperse particle-size distributions in laboratory air and in the field measured with and without the lines to be calibrated. Because of the system design, loss differences between the ten inlet lines were insignificant. Thus, the field results given below are corrected with one overall loss-correction function. The measured transmissions have been approximated by a third-order polynomial function. Due to

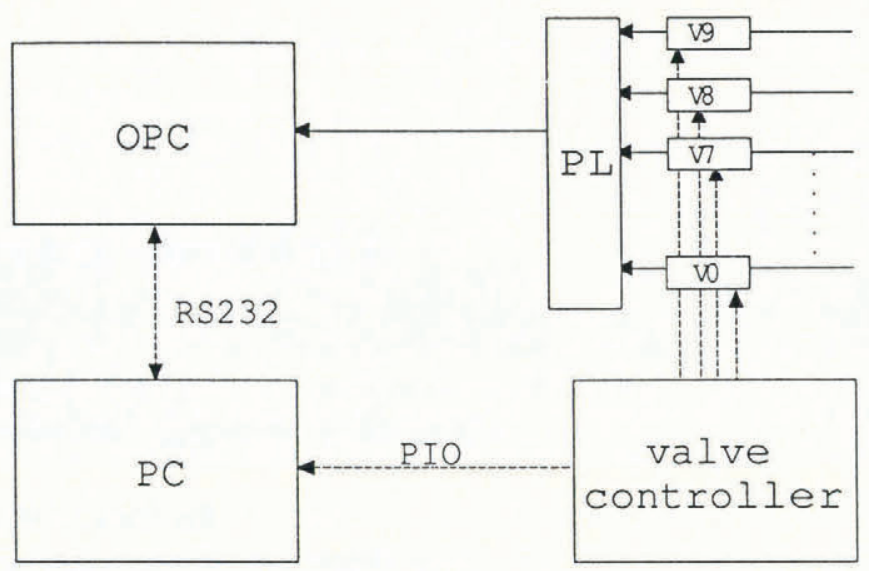

Fig. 1. Schematic picture of the electrical set-up of the particle profiler $O P C=P M S A S A S P X-100$ optical particle counter. $P C=$ lap-top personal computer; $P I O=$ parallel input-output port; $P L=9 \mathrm{~cm}^{3}$ sample plenum; $R S 232=$ serial port; $V 0-V 9=$ magnetic valves.

sedimentation in the sample lines, transmission decreases rapidly with particle size above $2 \mu \mathrm{m}$ diameter. This fact is another reason for terminating the study at the upper end of the accumulation mode.

\section{THE FIELD EXPERIMENT}

In March 1991, we conducted an exploratory field experiment near $\mathrm{Ny}$-Ålesund, Vestspitsbergen $\left(79^{\circ} \mathrm{N}\right.$, $12^{\circ} \mathrm{E}$ ) to test the snow profiler. The instruments were set up in a field station located about $1 \mathrm{~km}$ from the main research station. A c. $20 \mathrm{~cm}$ deep pit was dug in a compact old snow pile on the upwind side of the house. The inlets were set up as shown schematically in Figure 2. They were supported and spaced by $\Delta z=4 \mathrm{~cm}$ with a wooden stick. The opening of the pit had an area $A_{\text {pit }}$ of about $710 \mathrm{~cm}^{2}$. With the volumetric flow $F_{\text {OPC }}$ of the sensor, a snow-covered opening in an otherwise closed pit of this size yields a face velocity $u_{0}$

$$
u_{0}=\frac{F_{\mathrm{OPC}}}{A_{\mathrm{pit}}}=1.4 \times 10^{-3} \mathrm{~cm} \mathrm{~s}^{-1}
$$

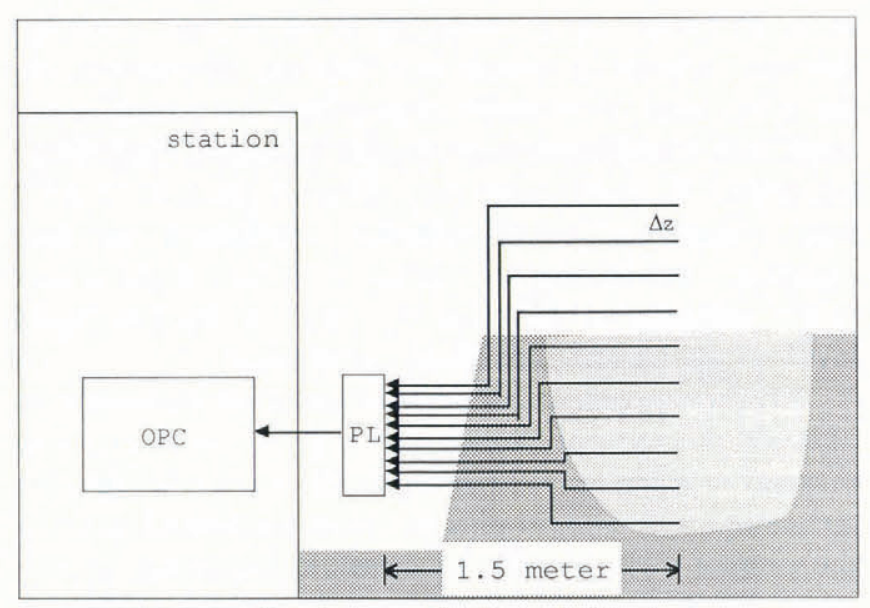

Fig. 2. Schematic picture of the particle profiler in the field experiment in $\mathcal{N} y$-Alesund, Vestspitsbergen. $\Delta z=4 \mathrm{~cm}$. All ten intakes have the same length. See Figure 1 for further details. 
which is on the order of the superficial air speed proposed by Schwander (1989) for the ventilation in snow.

From 16 to 21 March, ambient conditions allowed the recording of profiles. However, the air intakes did not become snow-covered before $20 \mathrm{March}$. The next day the experiment had to be terminated because freezing rain covered the outdoor instruments and closed off the inlets from the ambient air. Most of the time the system was run with a $2 \mathrm{~min}$ average time per size distribution of the $\mathrm{OPC}$ and $10 \mathrm{~min}$ sampling time per valve. The results of valve zero were discarded because they showed some cross-talk due to valve 9 not closing completely. It should be noted, though, that this interference was on the order of $1 / 1000$ of the value for valve 9 and that it was not noticeable in the next higher channel (number 1).

\section{RESULTS AND DISCUSSION}

A first overview of the results can be found in Figure 3 which gives isolines of corrected number concentrations at the nine intakes as a function of time. The graph shows clearly that on $20 \mathrm{March}$ around $0300 \mathrm{~h}$ snowfall started covering the lowest intakes. As is common in polar regions, much of the snow deposit was due to wind-blown snow settling in the pit. At about $0800 \mathrm{~h}$, the deposition process stopped and particle profiles stabilized at about $1000 \mathrm{~h}$. At this time, inlets 1 through 5 were snowcovered, 5 being about $1 \mathrm{~cm}$ below the surface while intakes 6 through 9 sampled air above the snow surface. With the exception of a particle intrusion around $1600 \mathrm{~h}$, they remained relatively stable until $2200 \mathrm{~h}$. Soon after, freezing rain started to influence sampling conditions. Consequently, we chose the period $1000-2200 \mathrm{~h}$ for the detailed study of average profiles.

In Figure 4 average profiles of $N$ and $V$ are presented. They have been calculated relative to the corresponding values in air above the snow (averaged over intakes 6-9). At $1 \mathrm{~cm}$ below the snow surface, about $40 \%$ of the

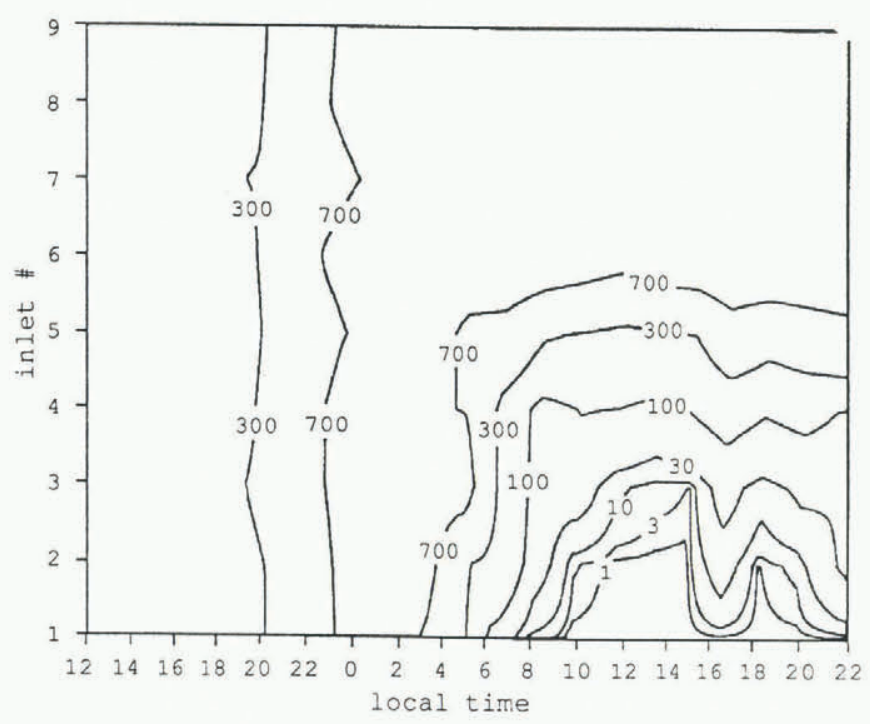

Fig. 3. Isolines of number concentrations $\left(\mathrm{cm}^{-3}\right)$ of airborne particles in and above the surface of a small snowfilled pit. The $x$-axis is divided in local time of 19 and 20 March at $\mathcal{N} y$-Allesund, Vestspitsbergen.

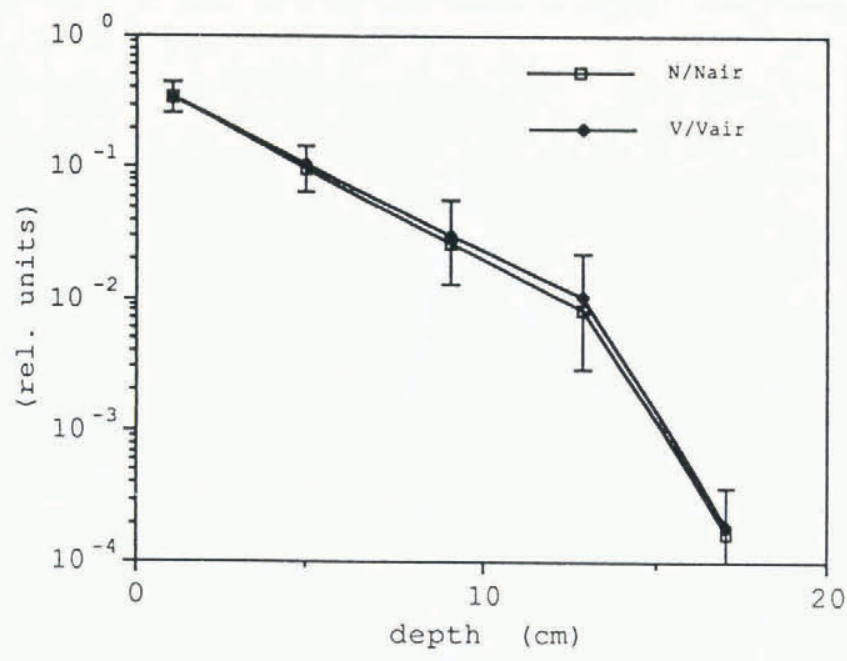

Fig. 4. Average relative depth profiles of airborne total number and total volume of particles in the diameter range $0.1 \leq d_{\mathrm{p}} \leq 2 \mu \mathrm{m}$. Concentrations are normalized to the average corresponding values in the four valves above the snow surface. The error bars show 1 standard deviation about the mean.

average particle number and volume for the layers 3$15 \mathrm{~cm}$ above the snow were left. This ratio decreases approximately exponentially down to $13 \mathrm{~cm}$ below the surface where about $1 \%$ of the air concentrations are present in the pores of the snow. Concentrations at the deepest usable intake $(17 \mathrm{~cm}$ depth) were much lower than an exponential decay would predict. We attribute this to the proximity of the bottom of the pit where ventilation was increasingly obstructed by the closely packed old surrounding snow.

The increasing uncertainty of the profiles with depth is due to decreasing particle concentrations which lead to increasing statistical errors in the OPC.

The similarity of the profiles for $N$ and $V$ is not selfevident. The number-size distribution is weighted by $d_{\mathrm{p}}^{3}$ when deriving volume- (or mass-) size distributions and subsequent integrals. Thus, more weight is put on larger particles in the total volume compared to $N$. As will be discussed below, particle retention in snow is sizedependent. However, the profiles for $N$ and $V$ are essentially identical. A look at the volume-size distribution as a function of depth indicates why this is so. These results are plotted in Figure 5 together with average air data. There is one major peak of the volume-size distribution around $350 \mathrm{~nm}$ and a minor contribution at a size of $1000 \mathrm{~nm}$ and above. This finding is typical for aerosols in polar regions with only minor sources of crustal material and sea salt (Heintzenberg, 1980). Around the peak size of these distributions, the deposition processes for particles is at a minimum. Thus, atmospheric ageing processes tend to yield such distributions in remote areas. As a consequence of this nearmonodisperse aerosol, the number- and volume-size distributions do not differ markedly and their respective depth profiles are very similar.

There is a further consequence of the shape of the distribution and the location of its peak size. Because the effectiveness of the deposition processes increases towards smaller and larger sizes than the peak shown here, we 


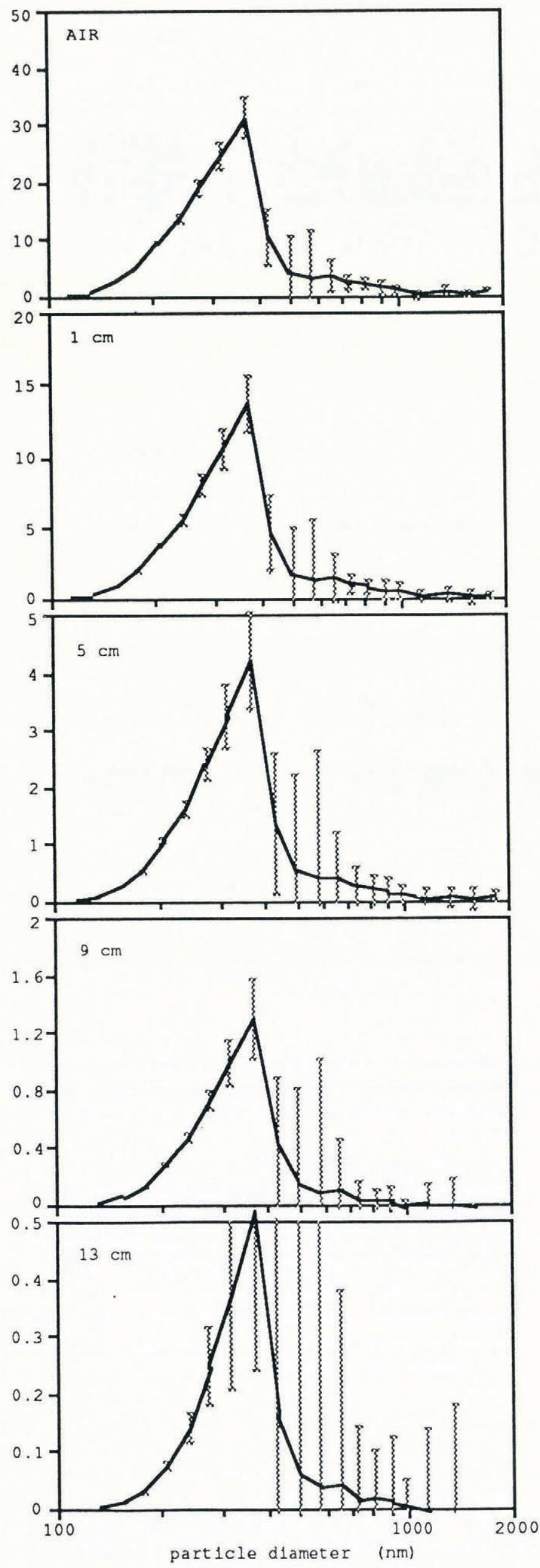

would expect the distribution to become narrower with depth. Indeed, the half-width of the volume distributions as shown in Figure 5 decreases linearly from $155 \mathrm{~nm}$ at $1 \mathrm{~cm}$ to $143 \mathrm{~nm}$ at $13 \mathrm{~cm}$ depth with a further strong decrease to $130 \mathrm{~nm}$ at $17 \mathrm{~cm}$ (not shown in Figure 5).

Classical filter theory (Fuchs, 1964) can be used to describe the decrease of the particle concentration $c$ with depth $z$ in a homogeneously filtering snow. We define a retention coefficient $\alpha$ in Equation (1)

$$
\ln \left(\frac{c_{z}}{c_{0}}\right)=-\alpha z
$$

This coefficient $\alpha$ is size-dependent because several sizedependent retention processes act on the particles. The total particle retention $\left(1-c / c_{0}\right)_{\mathrm{T}}$ can be written as the sum of the effects of diffusion (D), impact (I) and interception $(\mathbf{R})$

$$
\left(1-\frac{c}{c_{0}}\right)_{\mathrm{T}}=\left(1-\frac{c}{c_{0}}\right)_{\mathrm{D}}+\left(1-\frac{c}{c_{0}}\right)_{\mathrm{R}}+\left(1-\frac{c}{c_{0}}\right)_{\mathrm{I}}+\left(1-\frac{c}{c_{0}}\right)_{\mathrm{IR}} \text {. }
$$

According to Fuchs (1964), an interaction term (IR), between impact and interception, needs to be taken into account. The superposition of the terms in Equation (2) yields a size-dependence of $\left(1-c / c_{0}\right)_{\mathrm{T}}$ leading from a value of 1 at very small sizes via a minimum between 100 and $1000 \mathrm{~nm}$ to another asymptotic limit of 1 at large sizes. For fibrous filters, Lee and Liu (1980) have treated the most penetrating size as a function of filter parameters both theoretically and experimentally. In our pilot experiment, we did not have sufficient information available to apply a detailed filter model to the measured profiles. However, our results can be used to quantify $\alpha$ as a function of particle size in the most critical range between 100 and $1000 \mathrm{~nm}$.

We calculated average slopes $\alpha\left(d_{\mathrm{p}}\right)$ for the line in Equation (1) for the three $\Delta z$ intervals from 1 to $13 \mathrm{~cm}$ depth. Standard deviations of the average slopes were determined as a measure of the uncertainty in the profiles. Above $500 \mathrm{~nm}$ diameter, particle concentrations were too low to allow the determination of $\alpha$ at all depths. In order to derive information on large particles, we calculated average depth profiles of all channels above $500 \mathrm{~nm}$ and ascribed them to the geometric mean channel of $960 \mathrm{~nm}$. The results for $\alpha\left(d_{\mathrm{p}}\right)$ are shown in Figure 6 .

The shape of the curve and the location of the minimum value of $\alpha\left(d_{\mathrm{p}}\right)$ is in good agreement with general filter behavior as discussed in Lee and Liu (1980). At the minimum efficiency size the $1 / e$ depth is about $4 \mathrm{~cm}$. The change in uncertainty with particle size simply reflects the fact that absolute number-size distributions have their maximum at about $200 \mathrm{~nm}$ diameter. The results presented in Figure 6 provide the explanation for the sharpening of the size distributions with depth as shown in Figure 5.

$\triangle$ Fig. 5. Average profile of volume-size distributions given as $\mu \mathrm{m}^{3} \mathrm{~cm}^{-3}$ in air and at snow depths $1,5,9$ and $13 \mathrm{~cm}$. Error bars mark 1 standard deviation about the mean. At $13 \mathrm{~cm}$ depth, the error bars of the channels between 400 and $600 \mathrm{~nm}$ are larger than the frame of the graph (170, 190 and $160 \%$, respectively). 


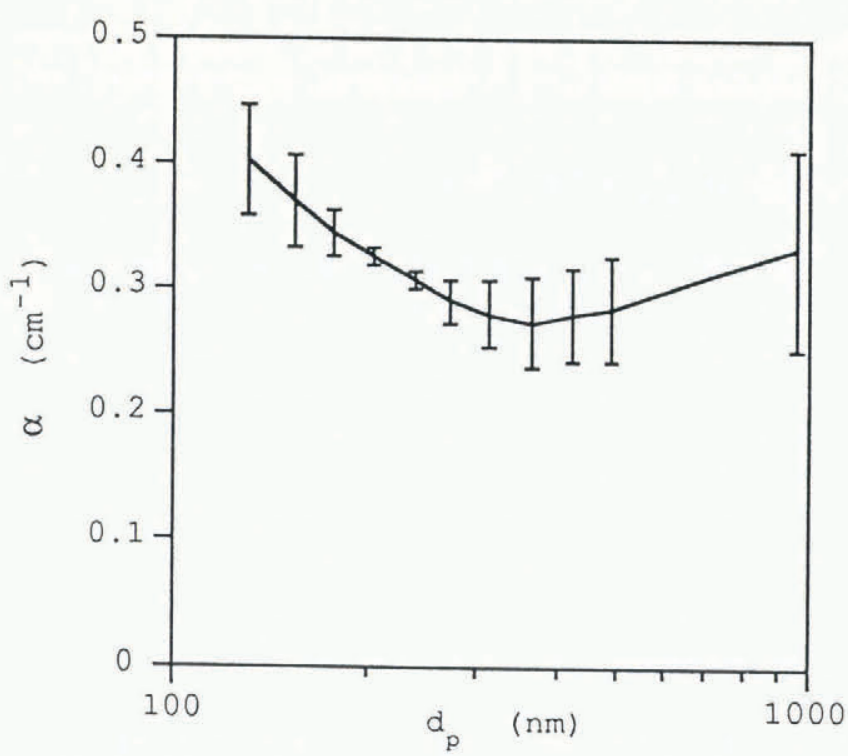

Fig. 6. Size-dependence of the retention coefficient $\alpha\left(d_{\mathrm{p}}\right)$ in $\mathrm{cm}^{-1}$ between 1 and $13 \mathrm{~cm}$ snow depth. All data above $500 \mathrm{~nm}$ have been collected in one average channel at the geometric mean size.

\section{MODEL CALGULATIONS}

We incorporated our results into a simple deposition model in order to give rough estimates of the effect of the penetration of airborne particles into snow on the distribution of impurities in the snowpack. In this timedependent model, atmospheric particle concentrations (units in $\mathrm{cm}^{-3}$ ) either have a constant value $C_{\mathrm{av}}$ or $C_{\mathrm{av}}$ and a superimposed annual periodic forcing of the form

$$
C_{i}=C_{\mathrm{av}}+\frac{1}{2} A \sin (2 \pi i \Delta t / T) \quad i=1, \ldots, n
$$

where $A$ is amplitude of the annual wave, $\Delta t$ is time step and $n$ is total number of layers. For the present purpose, the period $T$ of the forcing is held fixed at 1 year.

Two deposition processes add material to each deposited layer with a thickness $\Delta d=R \Delta t$. For the present study, a time-independent accumulation rate $R$ in $\mathrm{cm}$ year $^{-1}$ is used. At the present snow surface, dry deposition with a velocity $u_{\mathrm{d}}$ takes place, yielding at each time step $i \Delta t$ the amount of deposited material multiplied by the product of the dry-deposition flux (per unit of surface) and the time step $\Delta t$

$$
C_{i} u_{\mathrm{d}} \Delta t .
$$

Ventilation with a speed $u_{\mathrm{v}}$ takes place in the accumulating snow layer. The amount which is deposited at each depth $d=R i \Delta t$ at the time step $\Delta t$ is calculated by taking the difference of the total amount deposited down to $d+0.5 \Delta d$ and that down to $d-0.5 \Delta d$ :

$C_{i} u_{\mathrm{v}} \Delta t\left\{1-\exp \left(\alpha\left(d+\frac{1}{2} \Delta d\right)\right)-\left(1-\exp \left(\alpha\left(d-\frac{1}{2} \Delta d\right)\right)\right)\right\}$.

In the present model, the filtering effect of the snow is constant with depth and is described by the retention coefficient $\alpha$. Re-arranging and replacing $\Delta d$ by $R \Delta t$ yields

$C_{i} u_{\mathrm{v}} \Delta t\left\{\exp \left(\alpha R\left(i \Delta t-\frac{1}{2} \Delta t\right)\right)-\left(\exp \left(\alpha R\left(i \Delta t+\frac{1}{2} \Delta t\right)\right)\right)\right\}$.
After the evolution of $n$ time steps, corresponding to the accumulation of a snow layer with a total depth of $R n \Delta t$, the total amount of deposited material at any depth $d_{i}=R i \Delta t$ is calculated by the sum of the surface deposition at the time that the layer was formed

$$
C_{i} u_{0} \Delta t
$$

plus the corresponding sums of ventilation terms according to Equation (5)

$$
\begin{aligned}
& \sum_{j=1}^{i} C_{j} u_{\mathrm{v}} \Delta t\left\{\exp \left(\alpha R\left(j \Delta t-\frac{1}{2} \Delta t\right)\right)-\right. \\
&\left.\left(\exp \left(\alpha R\left(j \Delta t+\frac{1}{2} \Delta t\right)\right)\right)\right\} .
\end{aligned}
$$

By changing the essential parameters of the model $A, \alpha, R, u_{\mathrm{d}}$ and $u_{\mathrm{v}}$, we explored the effect of ventilation on the distribution of deposited material in a homogeneous snowpack. In the first case, we kept air concentrations constant with time and varied the ratio of velocities $u_{\mathrm{v}} / u_{\mathrm{d}}$ for the minimum retention coefficient $a_{\min }=0.27$, which we had measured at about $350 \mathrm{~nm}$. Since the driving forces in the two processes are given by $u_{\mathrm{v}}$ and $u_{\mathrm{d}}$, it is their ratio that determines the relative importance of ventilation for the deposition of material in snow. As indicated in the introduction, very little is known about the relative magnitude of $u_{\mathrm{v}}$ and $u_{\mathrm{d}}$. For dry-deposition, velocities $u_{\mathrm{d}}$ to snow-surface values between 0.01 and $0.2 \mathrm{~cm} \mathrm{~s}^{-1}$ have been reported (DeWalle, 1987; Davidson and others, 1989), while values between 0.001 and 1 have been discussed for $u_{\mathrm{v}}$ (Dubrovin, 1961; Schwander, 1989). The results which are independent of $R$ are given in Figure 7. A $50 \%$ ventilation fraction is reached when both velocities are roughly equal. Because of the limited information available on the deposition processes on and in snow, the results in Figure 7 may give a rough estimate of the importance of ventilation in different settings.

Naturally, deposition by ventilation also depends on the retention coefficient $\alpha$. We explored this dependency by modeling the deposition processes for periodically varying particle concentrations in air according to Equation (1). In the case of annual variations, the accumulation rate $R$ determines the time (or depth) at which deposition conditions stabilize. All results in Figure 8 have been calculated for that stable state (and varying absolute depths). In order to quantify the effect of

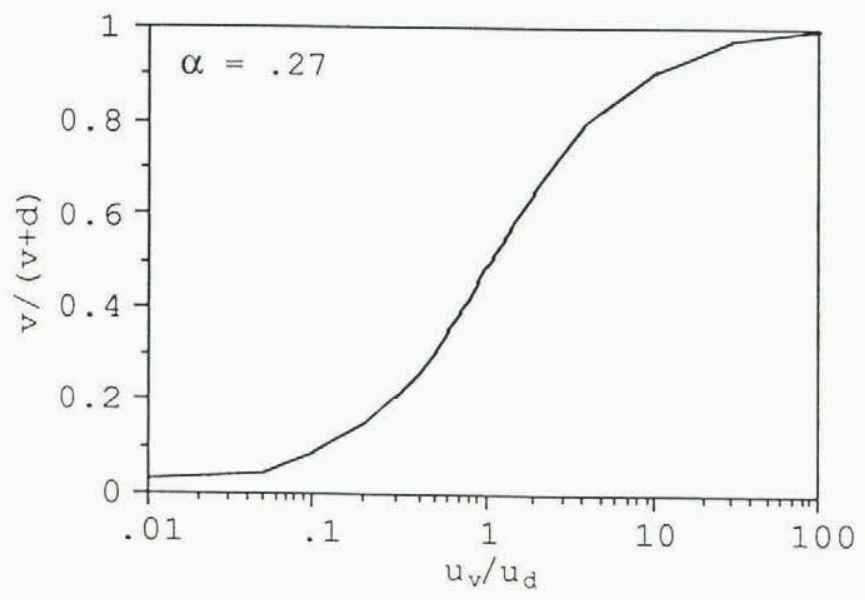

Fig. 7. Relative magnitude of ventilation $(v /(d+v))$ in the two-process deposition as a function of $u_{\mathrm{v}} / u_{\mathrm{d}}$ for the minimum measured retention coefficient $\alpha_{\min }=0.27$. 


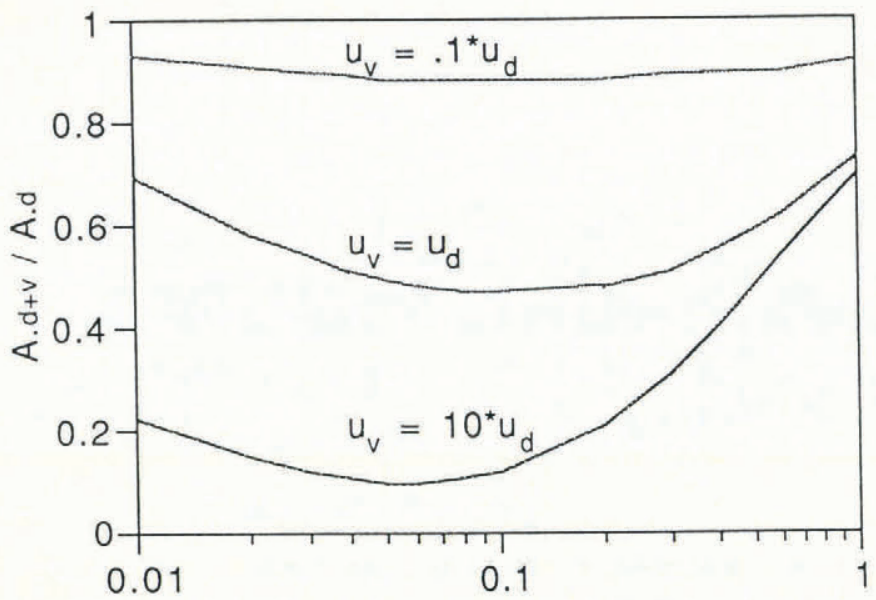

$\alpha$

Fig. 8. The ratio of annual amplitude in deposited material with and without snow ventilation as a function of retention coefficient $\alpha$ and of the relative magnitude of ventilation speed $u_{\mathrm{v}}$ versus surface deposition velocity $u_{\mathrm{d}}$.

ventilation on the profile of deposited material, we calculated the ratio of annual amplitudes in deposited concentrations with and without ventilation. This ratio $A_{\mathrm{d}+\mathrm{v}} / A_{\mathrm{d}}$ is plotted for different velocity ratios and retention coefficients in Figure 8 . For all velocity ratios, the shape of the $\alpha$ dependencies are the same. At very high $\alpha$ values, snow ventilation dampens annual variations strongly because of the high retention effect. At very low $\alpha$ values, on the other hand, the dampening effect is also high because particles ventilated into the snow penetrate very deep. The level difference of the three curves in Figure 8 are in accordance with Figure 7. It is interesting to see in Figure 8 that there are deposition conditions conceivable where annual variations in the air are dampened to about $90 \%\left(\alpha=0.06, u_{\mathrm{v}}=10 u_{\mathrm{d}}\right)$.

\section{CONCLUSIONS}

The short pilot experiment described above was not intended to provide a comprehensive picture of airborne particles in snow. However, a number of conclusions can be drawn which are important for environmental and paleoclimatological studies. Airborne particles can be used as tracers in newly deposited snow down to $17 \mathrm{~cm}$ below the surface. With a suitable particle sensor, snow ventilation at the level of expected natural values can be measured. The air/snow exchange of these particles must be considered in the interpretation of impurities in snow and glacier ice. However, the relative magnitude of ventilation velocity compared to dry-deposition velocities at the surface is of crucial importance for the magnitude of the ventilation effect on total deposition. In particular, in ice sheets with high ventilation velocities, seasonal variations in atmospheric concentrations will be leveled out and the age distributions of deposited particles need to be considered as in the occlusion of gases. With the help of modern theory for fibrous filters and some additional information derived for future experiments such as the pressure drop from the surface to the sampling points and snow density, it should be possible to derive a comprehensive description of the filtration properties of snow.

\section{ACKNOWLEDGEMENTS}

We should like to thank J. Ogren for providing us with the software to run the particle counter with a PC, to read the position of the valve controler, and to do the primary data reduction. L. Bäcklin designed and built the valves and the controler which worked while snow-covered at $-15^{\circ} \mathrm{C}$. S.- $\AA$. Odh's help with the set-up in the laboratory and in the field is gratefully acknowledged. S. Haarala kindly provided the isoline plot in Figure 3.

\section{REFERENCES}

Bader, H. 1939. Mineralogische und strukturelle Charakterisierung des Schnees und seiner Metamorphose. Beitr. Geologie der Schweiz, 3.

Davidson, C. I., J. R. Harrington, M. J. Stephenson, M.J. Small, F. P. Boscoe and R. E. Gandley. 1989. Seasonal variations in sulfate, nitrate and chloride in the Greenland ice sheet: relation to atmospheric concentrations. Atmos. Environ., 23, 2483-2493.

DeWalle, D. R. 1987. Review of snowpack chemistry studies. In Jones, H. G. and W.J. Orville-Thomas, eds. Seasonal snowcover: physics, chemistry, hydrology. Dordrecht, etc., D. Reidel Publishing Co., 255-268.

Dubrovin, L. I. 1961. Air currents in the snow and firn layer of Lazarev Ice Shelf. Inf. Bull. Sov. Antarct. Exped. 3, 1965, 218-219.

Fuchs, N.A. 1964. The mechanics of aerosols. Oxford, etc., Pergamon Press.

Gjessing, Y.T. 1977. The filtering effect of snow. International Association of Hydrological Sciences Publication 118 (Symposium at Grenoble 1975 - Isotopes and Impurities in Snow and Ice), 199-203.

Gjessing, Y.T. and E.T. Gjessing. 1973. Chemical composition of an Antarctic snow profile. Vatten, 3, 233-237.

Heintzenberg, J. 1980. Particle size distribution and optical properties of Arctic haze. Tellus, 32(3), 251260.

Knollenberg. 1985. The measurement of particle sizes below 0.1 micrometers. F. Environ. Sci., 13, 32-47.

Lee, K.W. and B.Y.H. Liu. 1980. On the minimum efficiency and the most penetrating particle size for fibrous filters. APCA Journal, 30, 377-381.

Reuter, H. 1948. Über die Theorie des Wärmehaushaltes einer Schneedecke. Arch. Meteorol. Geophys. Bioklimatol., Ser. $A, \mathbf{1}(1), 62-92$.

Schwander, J. 1989. The transformation of snow to ice and the occlusion of gases. In Oeschger, H. and C. C. Langway, Jr, eds. The environmental record in glaciers and ice sheets. Chichester, etc., John Wiley and Sons, 53-67.

Whitby, K. T. 1978. The physical characteristics of sulfur aerosols. Atmos. Environ., 12, 135-159.

The accuracy of references in the text and in this list is the responsibility of the authors, to whom queries should be addressed. 